\title{
Experiência e relato pessoal sobre pesquisa de cooperação internacional - Brasil, Bulgária e Turquia - que avalia as atitudes em relação à gagueira ${ }^{* * * * *}$
}

\author{
Experience and personal report about an international cooperation \\ research- Brazil, Bulgaria and Turkey - Attitudes Toward Stuttering
}

Kenneth O. St. Louis* (kstlouis@wvu.edu)

Claudia Regina Furquim de Andrade**

Dobrinka Georgieva***

Filiz Oruç Troudt****

\begin{abstract}
*Fonoaudiólogo. Professor Associado - Department of Speech Pathology and Audiology, West Virginia University.

**Fonoaudióloga. Professora Titular do Departamento de Fisioterapia, Fonoaudiologia e Terapia Ocupacional da Faculdade de Medicina da Universidade de São Paulo.

***Fonoaudióloga. Professora Associada - Department of Logopedics of South-West University.

****Fonoaudiólogo. Doutorado pela Louisiana State University Health Sciences Center.

******Trabalho Realizado no Department of Speech Pathology and Audiology, West Virginia University.
\end{abstract}

Artigo de Opinião

Artigo Submetido a Avaliação por Pares Conflito de Interesse: não

Recebido em 7.06.2005.

Revisado em 10.07.2005; 19.07.2005; 13.09.2005.

Aceito para Publicação em 13.09.2005.

\section{Abstract}

Background: people typically regard stutterers as shy, nervous, introverted, and fearful, a so-called "stuttering stereotype". Many stutterers are also subjected to teasing and bullying or to illegal discrimination. Aim: currently, there are no widely-accepted, standardized instruments used to measure public attitudes toward stuttering around the world. Accordingly, an International Project on Attitudes Toward Stuttering (IPATS) initiative was launched in 1999 to develop such an instrument, named the Public Opinion Survey of Human Attributes (POSHA). Method: this study compares selected results from three groups of adults from countries in South America (Brazil), Eastern Europe (Bulgaria), and the Middle East (Turkey). Respondents were pooled into three groups according to place-of-residence variable by country and a survey language variable. All of the respondents completed the questionnaire in the primary language of their countries. Results and Conclusion: this pilot study suggests that some attitude differences among respondents may be explained by an interaction of national, cultural, ethnic, religious, or language differences, although the relative contribution of each component cannot be determined. In a subsequent tier of survey analyses, ratings by these respondents will be compared with the ratings of respondents from other countries completing the survey in English.

Key Words: Stuttering; Evolution; Social Perception.

\section{Resumo}

Tema: as pessoas gagas são freqüentemente consideradas como sendo tímidas, nervosas, introvertidas e assustadas. Muitos gagos são submetidos a situações constrangedoras em decorrência da ridicularização ou da discriminação e preconceito ilegal. Objetivo: até o momento não existe nenhum instrumento, largamente aceito e padronizado, para medir as atitudes públicas sobre a gagueira. Em 1999 foi iniciado o Projeto de Atitudes em Relação à Gagueira (IPATS) que foi uma iniciativa para desenvolver um instrumento de avaliação de opinião, que foi chamado de Pesquisa de Opinião Pública dos Atributos Humanos (POSHA). Método: a experiência aqui apresentada compara os resultados obtidos em três países - Brazil, a Bulgária e a Turquia, como representantes da América do Sul, da Europa e do Oriente Médio. Os participantes foram agrupados segundo seu país e língua de origem. Todos os questionários foram respondidos na língua de origem do participante. Resultados e Conclusão: esse estudo piloto sugere que algumas diferenças de atitudes entre os participantes podem ser explicadas pela influência da interação entre a nacionalidade, cultura, etnia, religião e língua materna. A contribuição específica de cada um desses componentes não pode ser determinada. A continuidade do projeto envolverá a análise comparativa entre os resultados dos países de língua materna não inglesa e os de língua materna inglesa.

Palavras-Chave: Gagueira; Avaliação; Percepção Social. 
As pessoas gagas são freqüentemente consideradas como sendo tímidas, nervosas, introvertidas e assustadas (Shapiro, 1999). Muitos gagos são submetidos a situações constrangedoras em decorrência da ridicularização ou da discriminação e preconceito ilegal (Blood, 1999). Em resposta a essas atitudes pejorativas ou de ignorância do público algumas iniciativas de sensibilização pública e campanhas educacionais tem sido formuladas, tendo como objetivo promover atitudes positivas.

Até o momento não existe nenhum instrumento, largamente aceito e padronizado, para medir as atitudes públicas sobre a gagueira. Em 1999 foi iniciado o Projeto de Atitudes em Relação à Gagueira (Ipats) que foi uma iniciativa para desenvolver um instrumento de avaliação de opinião, que foi chamado de Posha (Pesquisa de Opinião Pública dos Atributos Humanos). A proposição foi elaborada por St. Louis, et al. em 2001. Esse instrumento é composto por uma parte geral (que compara a gagueira a outros oito atributos considerados como "âncoras" - como inteligência, preferência manual e doença mental), por uma parte específica sobre a gagueira e por uma parte de caracterização demográfica. Esse instrumento foi aplicado em vários países, envolvendo aproximadamente 900 adultos entrevistados que completaram o questionário representando a primeira, de duas versões experimentais do instrumento. O Posha-E1 é composto pela marcação de descritores com escalas contínuas. O Posha-E2 é composto pela marcação numérica de 1 a 9 (circular o número).

A experiência aqui apresentada compara os resultados obtidos em três países - Brasil, a Bulgária e a Turquia, como representantes da América do Sul, da Europa e do Oriente Médio. Os participantes foram agrupados segundo seu país e língua de origem. Todos os questionários foram respondidos na língua de origem do participante. A tabela 1 apresenta o perfil demográfico do estudo.

TABELA 1. Perfil demográfico.

\begin{tabular}{cccc}
\hline & Brasil & Bulgária & Turquia \\
\hline total de participantes & 188 & 14 & 25 \\
sexo & $65 \% \mathrm{M}-35 \% \mathrm{H}$ & $75 \% \mathrm{M}-25 \% \mathrm{H}$ & $50 \% \mathrm{M}-50 \% \mathrm{H}$ \\
média de idade & 27,4 & 41,2 & 29,3 \\
estado civil & $68 \%$ solteiros & $50 \%$ casados & $54 \%$ solteiros \\
raça & $55 \%$ brancos & $100 \%$ europeus & $100 \%$ turcos \\
religião & $72 \%$ católicos & $90 \%$ cristãos ortodoxos & $100 \%$ muçulmanos \\
língua materna & $100 \%$ Português & $100 \%$ Búlgaro & $100 \%$ Turco
\end{tabular}

Legenda: $\mathrm{M}=$ mulheres; $\mathrm{H}$ = homens.

As taxas obtidas tanto no Posha-E1 quanto no Posha-E2 foram convertidas num contínuo de - 100 $\mathrm{a}+100$ como os extremos negativo e positivo. $\mathrm{O}$ zero representando a taxa neutra. A análise dos questionários permitiu uma extensa disponibilidade de dados. Testes de significância estatística foram aplicados. Os resultados indicam:

- as diferenças não foram significantes entre os três grupos quando a gagueira foi comparada com as outras oito características mas os brasileiros apresentaram as impressões gerais sobre a gagueira mais baixas. Os turcos foram os que apresentaram a menor disposição para serem gagos e os búlgaros apresentaram o menor conhecimento sobre o distúrbio;

- o quesito querer ser um gago foi considerado o atributo mais negativo, semelhante a ter sobrepeso, usar cadeira de rodas ou ter doença mental;

. significantemente, melhores atitudes caracterizaram os brasileiros em relação a etiologia da gagueira não atribuindo o distúrbio: aos vírus, às doenças, aos atos de Deus ou atos dos fantasmas/demônios/espíritos. Os turcos obtiveram mais pontos na atribuição da etiologia aos atos de Deus ou atos dos fantasmas/demônios/ espíritos; 
. os búlgaros foram os mais propensos e os brasileiros os menos propensos em acreditar que os gagos deveriam procurar ocupações que envolvessem a fala;

. os búlgaros foram os que menos acreditaram que os gagos apresentam diminuição da inteligência mas foram os que mais apresentaram pena dos gagos; . os turcos foram significantemente mais propensos a interferir na fala dos gagos, completando as palavras ou sugerindo que falassem mais devagar ou relaxadamente;

. os brasileiros indicaram serem menos preocupados se a professora do seu filho(a) for gaga mas apresentaram maior escore de preocupação caso seu filho(a) fosse gago (a).

Esse estudo piloto sugere que algumas diferenças de atitudes entre os participantes podem ser explicadas pela influência da interação entre a nacionalidade, cultura, etnia, religião e língua materna. A contribuição específica de cada um desses componentes não pode ser determinada. A continuidade do projeto envolverá a análise comparativa entre os resultados dos países de língua materna não inglesa e os de língua materna inglesa.

\section{Relato pessoal}

EUA: esse e outros estudos piloto tem apresentado os primeiros dados comparativos entre culturas e entre línguas em relação às atitudes para a gagueira. A relevância desse estudo foi que mesmo sendo aplicado em três diferentes traduções de uma pesquisa originalmente de língua inglesa, foram encontradas similaridades e diferenças nas atitudes dos grupos pesquisados. Os participantes, nas diferentes amostras, também parecem compreender e responder aos questionários com suficiente similaridade e seriedade, de maneira a fornecer comparações significativas.

Brasil: o estudo piloto envolveu a participação de 50 alunos de graduação em fonoaudiologia na atividade de campo. O estudo foi aplicado em duas cidades: São Paulo (SP) e Alfenas (MG). Houve um número pequeno de diferenças significantes entre as duas cidades. Os principais resultados encontrados no Brasil foram: a gagueira é considerada uma deficiência séria e o brasileiro tem um alto grau de desinformação e mal entendimento do que seja a gagueira.

Bulgária: o Posha foi distribuído em duas cidades da Bulgária, Sofia (capital) e Blagoevgrad. Dez estudantes de Fonoaudiologia da Universidade de South West distribuíram os questionários. Não foram encontradas diferenças óbvias entre os participantes das duas cidades. Os resultados da Bulgária incluíram algumas atitudes positivas em relação às pessoas com gagueira mas também alguns equívocos sobre esse distúrbio.

Turquia: o Posha foi traduzido e distribuído em quatro cidades do oeste da Turquia sendo que alguns participantes eram originários do leste da Turquia. O nível educacional dos participantes variava da escolaridade elementar à universitária. A resposta ao questionário foi positiva. Algumas pessoas incluíram um endereço de retorno para receber o resumo dos resultados. Os resultados na Turquia sugerem que a religião e a cultura foram fatores de influência na opinião pública sobre a gagueira. 


\section{Referências Bibliográficas}

BLOOD, G. W. The stigma of stuttering: centuries of negative perceptions and stereotypes. ASHA Convention, San Francisco, CA, 1999.

SHAPIRO, D. A. Stuttering intervention: a collaborative journey to fluency freedom. Austin, TX: Pro-Ed., 1999.
ST. LOUIS, K. O.; YARUSS, J. S.; LUBKER, B. B.; PILL, J.;

DIGGS, C. C. An international public opinion survey of stuttering: pilot results. In: Bosshardt, H. G.; Yaruss, J. S.; Peters H. F. M. (Eds.). Fluency disorders: theory, research, treatment and self-help. International Fluency Association, 2001. 